\title{
ANÁLISE ESPACIAL E TEMPORAL DE ESTRATÉGIAS DE RECUPERAÇÃO ENERGÉTICA DE SUBPRODUTOS DO TRATAMENTO DE ESGOTO NA REGIÃO METROPOLITANA DE CURITIBA
}

Resumo: Este artigo propõe estratégias para otimizar o aproveitamento energético de biogás e lodo em plantas de tratamento anaeróbio de esgoto (ETEs). A pesquisa é aplicada e descritiva, em um estudo de caso na região metropolitana de Curitiba. Os procedimentos utilizados foram: levantamento de dados qualitativos (documental) e quantitativos (secundários) das ETEs; simulação computacional da produção de biogás e lodo das ETEs; análise financeira e de desempenho das estratégias. As estratégias de recuperação energética obtidas foram (em 2043): secagem térmica e motogerador em 6 ETEs (1.680 MWh.mês ${ }^{-1}$ evitado); motogerador a biogás em 5 ETEs (655 MWh.mês ${ }^{-1}$ evitado); lodo para UGL e a queima do biogás em 18 ETEs. Conclusão: pelo menos $26 \%$ das ETEs apresentaram viabilidade de desempenho e financeira para aproveitamento do biogás e lodo em 2017 e 38\% em 2043.

Palavras-chave: Lodo Anaeróbio. Metano. Tratamento Térmico. Motogerador. Índice de desempenho.

\section{SPACE AND TIME ANALYSIS OF ENERGY RECOVERY STRATEGIES FOR WASTEWATER TREATMENT BY-PRODUCTS IN THE METROPOLITAN AREA OF CURITIBA}

\begin{abstract}
This article proposes strategies to optimize the energy use of biogas and sludge in anaerobic sewage treatment plants (WWTPs). The research is applied and descriptive, in a case study in the metropolitan region of Curitiba. The procedures used were: survey of qualitative (documentary) and quantitative (secondary) data from the WWTPs; computational simulation of the biogas and sludge production of the WWTPs; financial and performance analysis of strategies. The energy recovery strategies obtained were (in 2043): thermal drying and motor generator in 6 WWTPs (1,680 MWh.month ${ }^{-1}$ avoided); biogas engine in 5 WWTPs (655 MWh.month-1 avoided); sludge for integrated WWTP and the burning of biogas in 18 WWTPs. Conclusion: at least $26 \%$ of the WWTPs showed performance and financial viability for the use of biogas and sludge in 2017 and 38\% in 2043.
\end{abstract}

Keywords: Anaerobic Sludge. Methane. Thermal Drying. Power generator. Performance index.

\footnotetext{
${ }^{1}$ Companhia Brasileira de Projetos e Empreendimentos, COBRAPE, Curitiba, Brasil, tascho@gmail.com, https://orcid.org/0000-0002-7879-5910

${ }^{2}$ Núcleo de Estudos em Ecosocioeconomia, Universidade Federal do Paraná, Curitiba, Brasil, pb.bilotta@gmail.com, https://orcid.org/0000-0002-2463-2331
} 


\section{ANÁLISIS ESPACIAL Y TEMPORAL DE LAS ESTRATEGIAS DE RECUPERACIÓN DE ENERGÍA PARA EL TRATAMIENTO DE AGUAS RESIDUALES EN LA REGIÓN METROPOLITANA DE CURITIBA}

Resumen: Este artículo propone estrategias para optimizar el uso de energía del biogás y el lodo en plantas de tratamiento de aguas residuales anaeróbicas (PTAR). La investigación es aplicada y descriptiva, en un estudio de caso en la región metropolitana de Curitiba. Los procedimientos utilizados fueron: encuesta de datos cualitativos (documentales) y cuantitativos (secundarios) de las PTAR; simulación computacional de la producción de biogás y lodos de las PTAR; Análisis financiero y de desempeño de estrategias. Las estrategias de recuperación de energía obtenidas fueron (en 2043): secado térmico y generador de motor en 6 PTAR (1.680 MWh.mes ${ }^{-1}$ evitados); motor de biogás en 5 PTAR (655 MWh.mes ${ }^{-1}$ evitado); lodo para PTAR integrado y la quema de biogás en 18 PTAR. Conclusión: al menos el $26 \%$ de las PTAR mostraron rendimiento y viabilidad financiera para el uso de biogás y lodos en 2017 y el 38\% en 2043.

Palabras clave: Lodo anaeróbico. Metano. Tratamiento térmico. Generador de energía.

\section{Introdução}

As estações de tratamento de esgoto (ETEs) compreendem um complexo sistema de unidades operacionais projetadas de modo a adequar as características físicas, químicas e biológicas de efluentes de atividades humanas, segundo parâmetros e limites estabelecidos na legislação, com o objetivo de promover a saúde pública (controle de doenças de veiculação hídrica) e garantir a manutenção da qualidade ambiental (Jordão e Pessôa, 2011). Entretanto, as ETEs demandam elevado (e contínuo) consumo de energia, sobretudo diante de padrões mais restritivos de qualidade do efluente, que exigem a implantação de etapas de tratamento complementar. Esse cenário gera, consequentemente, sobrecarga no sistema de fornecimento de energia por parte das concessionárias, pois ETEs estão entre os maiores consumidores industriais, além de implicar em alto custo operacional ao tratamento de esgoto (25 a 40\% do custo total) (Fraia et al., 2018; Von Sperling, 2016).

Por outro lado, a recuperação energética do poder calorífico do gás metano $\left(\mathrm{CH}_{4}\right)$ e do lodo biológico, formados na degradação anaeróbia da matéria orgânica, é uma estratégia em potencial para atender a demanda crescente de energia do setor de saneamento (Rosa et al., 2018; Rosa et al., 2016; Carvalho, 2016; Possetti et al., 2012). A Tabela 1 compara a capacidade calorífica de alguns combustíveis (Mulinari et al., 2017; Rosa et al., 2019). 
No Brasil, os reatores anaeróbios do tipo UASB (Upflow Anaerobic Sludge Blanket) representam a segunda tecnologia mais utilizada no tratamento de esgoto (38\% das ETEs) - precedida apenas por sistemas de lagoas (41\% das ETEs) - e esse total corresponde ao atendimento de 51.878 .930 habitantes (Von Sperling, 2016).

Tabela 1 - Poder calorífico de alguns combustíveis.

\section{COMBUSTIVEL}

\begin{tabular}{|c|c|c|}
\hline COMBUSTIIVEL & \multicolumn{2}{|c|}{ PODER CALORÍFICO } \\
\hline Biogás $60 \% \mathrm{CH}_{4}$ (típico) & 6,0 kWh. $\mathrm{Nm}^{-3}$ & $5.143,8{\mathrm{kcal} . \mathrm{Nm}^{-3}}^{-3}$ \\
\hline Biogás $70 \% \mathrm{CH}_{4}$ & 7,0 kWh. $\mathrm{Nm}^{-3}$ & $5.995,0{\mathrm{kcal} . \mathrm{Nm}^{-3}}^{-3}$ \\
\hline Biogás $90 \% \mathrm{CH}_{4}$ (purificado) & 9,0 kWh. Nm ${ }^{-3}$ & $7.714,7{\mathrm{kcal} . \mathrm{Nm}^{-3}}^{-1}$ \\
\hline Gás natural & $10,8 \mathrm{kWh} \cdot \mathrm{Nm}^{-3}$ & $7.544,2{\mathrm{kcal} . \mathrm{Nm}^{-3}}^{-3}$ \\
\hline Metano & 10,0 kWh.Nm ${ }^{-3}$ & $8.572,9{\mathrm{kcal} . \mathrm{Nm}^{-3}}^{-3}$ \\
\hline Lodo seco $\left(65 \%\right.$ de ST) $\left(^{(*)}\left(^{(*)}\right.\right.$ & $0,6 \mathrm{kWh}_{\mathrm{kg}}{ }^{-1}$ & 501,6 kcal.kg-1 \\
\hline Lodo seco $\left(90 \%\right.$ de ST) $\left(^{(*)}\left(^{(*)}\right.\right.$ & $2,5 \mathrm{kWh} \cdot \mathrm{kg}^{-1}$ & $2.197,3{\mathrm{kcal} . \mathrm{kg}^{-1}}^{-1}$ \\
\hline Lodo seco $\left(95 \%\right.$ de ST) $\left(^{(*)}{\left({ }^{*}\right)}^{2}\right.$ & 3,8 kWh.kg- & $3.236,3{\mathrm{kcal} . \mathrm{kg}^{-1}}^{-1}$ \\
\hline Bagaço de cana de açúcar ${ }^{(*)}\left({ }^{* *}\right)$ & $4,8 \mathrm{kWh} \cdot \mathrm{kg}^{-1}$ & $4.132,0{\mathrm{kcal} . \mathrm{kg}^{-1}}^{-1}$ \\
\hline Madeira $\left(^{*}\right)\left(\left(^{*}\right)\right.$ & 5,0 kWh.kg-1 & $4.299,2{\mathrm{kcal} . \mathrm{kg}^{-1}}^{-1}$ \\
\hline
\end{tabular}

ST: Sólidos totais. ${ }^{*}$ Poder calorífico inferior. ${ }^{* *}$ Valor médio.

Fonte: Rosa et al. (2019); Mulinari et al. (2017).

O objetivo deste artigo é propor estratégias para otimizar o aproveitamento do potencial energético do biogás e do lodo em ETEs anaeróbias. Este estudo vem, portanto, de encontro a uma necessidade evidente, pois o país possui grande potencial instalado para recuperação energética do biogás e do lodo biológico, mas para que isso ocorra a contento deve-se buscar a gestão integrada desses recursos e soluções tecnológicas capazes de otimizar a relação entre saldo energético efetivo e investimento.

A área de estudo compreende as ETEs anaeróbias da Região Metropolitana de Curitiba (RMC). Segundo dados do Instituto Paranaense de Desenvolvimento Econômico e Social (IPARDES), em 2017 os municípios da RMC somavam 3.587.846 habitantes e para 2040 a projeção de crescimento dessa parcela da população é de 15\% (IPARDES, 2017). Em 2017 apenas 44\% da população dessa região era beneficiada com coleta e tratamento de esgoto e o plano diretor da companhia de saneamento do Paraná prevê a expansão desses serviços para $80 \%$ da população até 2043 (SANEPAR, 2015). Isso significa que o potencial energético instalado das ETEs da RMC deve dobrar em 25 anos. 


\section{Contextualização}

\section{Recuperação energética do biogás}

O biogás é constituído por uma mistura de gases em diferentes proporções metano (60 a $80 \%$ ), nitrogênio (10 a $25 \%$ ), dióxido de carbono (5 a 10\%) e traços de outros componentes ( 0 a $5 \%$ ), como sulfeto de hidrogênio, responsável pelo odor característico, monóxido de carbono, gás hidrogênio e amônia (Bilotta e Ross, 2016). ETEs com alta carga orgânica afluente e eficientes na remoção de DQO (demanda química de oxigênio) tendem a produzir mais metano, se respeitadas as condições para que a degradação anaeróbia ocorra (Noyola et al., 2006). A produção de biogás na digestão anaeróbia de esgoto pode variar entre 25 a 30 L.hab-1. dia-1 (Jordão e Pessôa, 2011).

O biogás proveniente de reatores anaeróbios pode ser empregado como combustível (em caldeiras, fornos, estufas, veículos) e na geração ou cogeração de energia (Chernicharo et al., 2015). Todavia, a conversão de energia química (armazenada no biogás) em outras formas de energia resulta, necessariamente, em perdas inerentes às tecnologias utilizadas (maior ou menor intensidade), por isso, é importante realizar o balanço energético do sistema e verificar a quantidade de energia disponível para a conversão pretendida (Metcalf e Eddy, 2016). Outros estudos apontam também o uso de biogás na secagem e higienização térmica do lodo em ETEs (Possetti et al., 2012; Borges et al., 2009).

Em termos de obtenção de energia elétrica, Bilotta e Ross (2016) contabilizaram a capacidade de geração de 65,3 MWh.mês ${ }^{-1}\left(65 \% \mathrm{CH}_{4}\right)$ em ETE que atende 190 mil habitantes, em Curitiba (59\% da demanda). Rosa et al. (2016) estimaram 27.408 kWh.mês ${ }^{-1}\left(78,2 \% \mathrm{CH}_{4}\right)$ para 70 mil habitantes $(57,6 \%$ da demanda) em Itabira/MG. Carvalho (2016) computou a oferta de 4,5 GWh.mês ${ }^{-1}$ (75\% $\mathrm{CH}_{4}$ ) em 219 ETEs com reator UASB no Paraná (5,87 milhões de habitantes). Uma vez que o poder calorífico do biogás se deve ao metano, quanto maior a parcela de $\mathrm{CH}_{4}$ na mistura gasosa, maior será a disponibilidade de energia (Tabela 1).

Existem alguns poucos registros de iniciativas de aproveitamento do biogás para geração de energia em plantas de tratamento de esgoto no Brasil. Alguns exemplos são: a ETE Arrudas (Belo Horizonte/MG) com a produção média de 20 MWh.mês ${ }^{-1}$ para cerca de 1 milhão de habitantes $(50 \%$ da demanda elétrica da 
planta) (COPASA, 2013); a ETE Ouro Verde (Foz do Iguaçu/PR) que produz energia suficiente para o funcionamento do medidor de vazão, da bomba de recalque do lodo e iluminação (SANEPAR, 2013); a ETE Betim (Minas Gerais), que utiliza biogás para alimentar um secador de lodo (COPASA, 2016); a ETE Ribeirão Preto (São Paulo) que atende 560 mil habitantes e gera cerca de $51 \%$ de toda a energia elétrica consumida pela planta (AMBIENT, 2014).

O projeto PROBIOGÁS, que resulta de uma cooperação entre o Ministério das Cidades (governo brasileiro) e a Gesellschaft für Internationale Zusammenarbeit (GIZ) (governo Alemão), tem apoiado pesquisas e iniciativas de recuperação do biogás para geração de energia, com o objetivo de expandir sua utilização no setor de saneamento, dentre outras atividades (BRASIL, 2015). Nesse sentido, o país possui grande potencial, pois cerca de $37,5 \%$ das ETEs operam atualmente com reatores UASB (Sperling, 2016).

Além da capacidade de geração de energia, a combustão do metano resulta em benefício ambiental direto, pela mitigação de emissão de gases de efeito estufa (GEE). Isso se deve à redução do potencial de aquecimento global (PAG) em 21 vezes (horizonte de 100 anos) na conversão de $\mathrm{CH}_{4}$ em $\mathrm{CO}_{2}$ na combustão do biogás (IPCC, 2015).

\section{Aproveitamento energético do lodo}

O lodo formado em reatores anaeróbios possui baixo teor de sólidos totais (3 a $5 \%$ em volume) e deve ser submetido a desaguamento, para reduzir custos com transporte e manejo, e sanitização, para controle de patogênicos, quando o seu destino é o uso agrícola (Jordão e Pessôa, 2011; Andreoli et al., 2001). Todavia, o lodo apresenta poder calorífico que o caracteriza como combustível em potencial (Tabela 1), podendo ser uma fonte alternativa para geração de energia em ETEs (Carneiro et al., 2020; Rosa et al., 2016).

A capacidade calorífica do lodo se deve à presença de carbono e hidrogênio. O carbono representa a maior parcela na composição elementar do lodo (20 a 35\% no lodo anaeróbio e 12 a 43\% no lodo aeróbio) em comparação ao hidrogênio (cerca de 4,5\%) (Rosa et al., 2019). Quanto maior o percentual de carbono e hidrogênio, maior será o poder calorífico da biomassa (Rosa et al., 2016). Todavia, o teor de sólidos totais interfere significativamente na quantidade de energia disponível 
(Tabela 1), pois na combustão há consumo de energia para evaporação de água. Portanto, quanto menor o teor de sólidos totais (ST), menor o poder calorífico útil do lodo (Carneiro et al., 2020; Rosa et al., 2019).

Dentre as alternativas de aproveitamento energética do lodo tem-se a incineração direta, por meio de secagem térmica (Mulinari et al., 2017), e a pirólise, menos utilizada, que consiste na queima do lodo na ausência de oxigênio (Tyagi e Lo, 2013). Na secagem térmica do lodo em ETEs anaeróbias tem-se a possibilidade de cogeração, pela recuperação conjunta do biogás e do lodo seco (80 a 85\% de ST) (Rosa et al., 2016).

Em termos de energia útil disponível, Mulinari et al. (2016) contabilizaram a

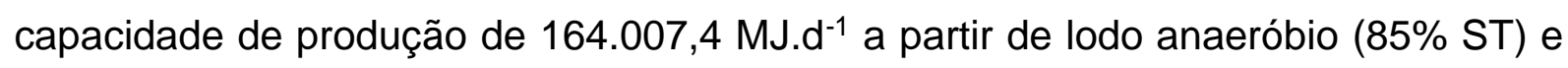
biogás de reatores UASB de uma ETE que atende 242 mil habitantes. Rosa et al.

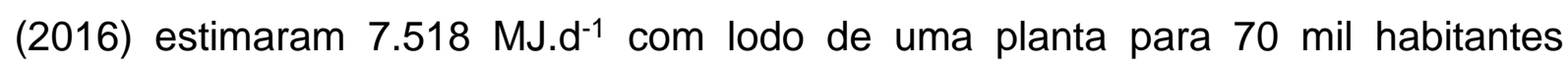
(58,7\% ST). Batistella (2015) obteve 14,6 MJ. kg-1 de lodo anaeróbio (81\% ST) e 10,5 MJ.kg-1 de lodo aeróbio ( $91 \%$ ST), valores semelhantes aos resultados alcançados por Rosa et al. (2019) (9,2 MJ.kg-1 de lodo anaeróbio com 70\% ST e 10,6 MJ.kg-1 de lodo aeróbio com $~ 85 \%$ ST).

\section{Procedimento metodológico Área de estudo}

Trata-se de uma pesquisa de natureza aplicada e descritiva em que se realizou o levantamento de dados qualitativos (documental) e quantitativos secundários, em um estudo de caso (período 2017 a 2019).

O estudo compreendeu todas as ETEs que operam com reator UASB localizadas na cidade de Curitiba e nos municípios da região metropolitana (Agudos do Sul, Almirante Tamandaré, Araucária, Balsa Nova, Bocaiúva do Sul, Campina Grande do Sul, Campo Largo, Cerro Azul, Colombo Contenda, Fazenda Rio Grande, Itaperuçu, Lapa, Mandirituba, Pinhais, Piraquara, Quatro Barras, Quitandinha, Rio Negro, São José dos Pinhais) (Figura 1). Utilizou-se dados quantitativos (características físicas e químicas do efluente das ETEs), para o potencial imediato de recuperação de energia das ETEs (ano base 2017) e para o cenário projetado (horizonte 2043), com base no plano diretor da companhia de saneamento. 
Para responder ao objetivo proposto, o estudo foi estruturado em cinco etapas: 1) estimativa da produção de biogás e lodo; 2) determinação da quantidade de energia útil disponível; 3) levantamento das características do secador térmico (equipamento utilizado para o aproveitamento energético do biogás e lodo seco); 4) avaliação da sustentabilidade energética; e 5) análise econômica. O detalhamento dos métodos e técnicas utilizadas em cada etapa é apresentado a seguir.

Figura 01 - Localização da região metropolitana de Curitiba.

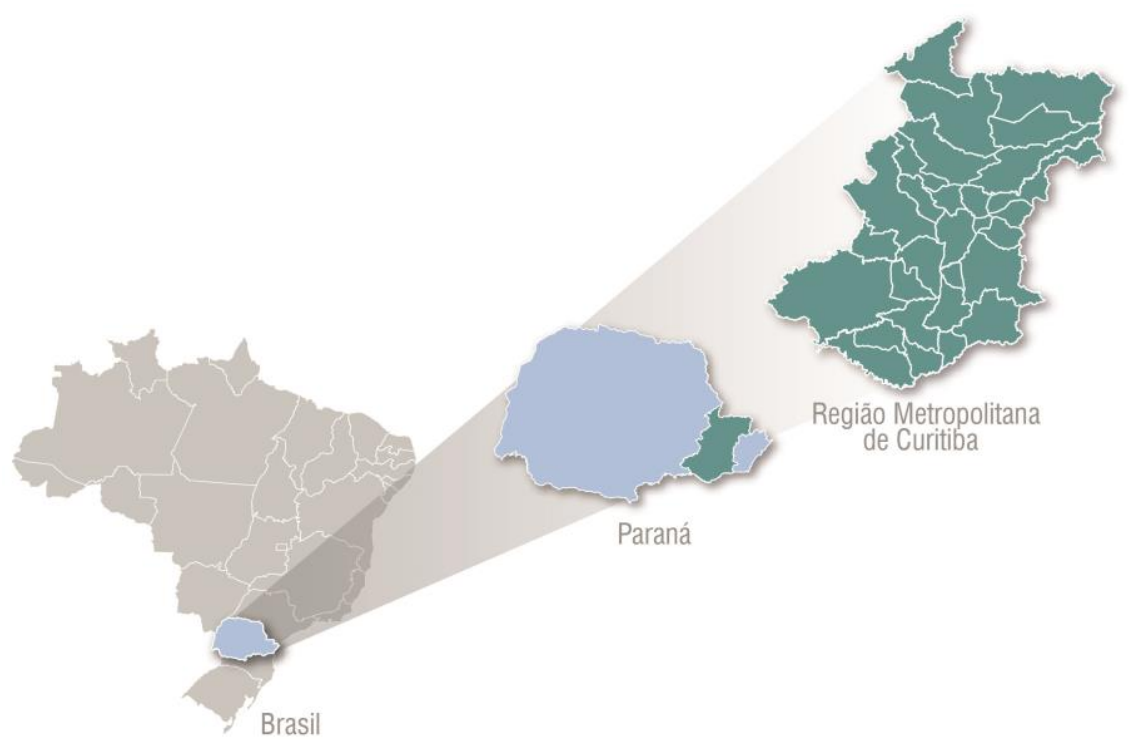

Fonte: Autor.

\section{Produção de biogás e lodo}

A produção de biogás foi estimada nos dois cenários (2017 e 2043) por meio do software Probio (versão 1.0) - programa computacional desenvolvido em uma parceria técnico-científica entre a Universidade Federal de Minas Gerais e a prestadora de serviços de saneamento do Paraná, que considera as rotas de conversão de matéria orgânica em reatores anaeróbios e perdas inerentes ao processo. Os dados de entrada do software foram população atendida e eficiência de remoção da DQO (demanda química de oxigênio) e a condição simulada foi a conservadora, por representar a maioria das ETEs analisadas.

A quantidade de lodo produzido foi determinada em uma consulta aos dados de monitoramento da prestadora de serviços de água e esgoto. Algumas ETEs, entretanto, não dispunham dessa informação e, nesses casos, utilizou-se a metodologia proposta por Rosa et al. (2018), que estimou a produção de lodo a 
partir da carga orgânica afluente (DQO) de um reator anaeróbio (equações 1, 2 e 3 Quadro 1).

Quadro 1 - Equações utilizadas para determinar a produção de lodo anaeróbio.

\begin{tabular}{|c|c|c|}
\hline \multirow{3}{*}{$D Q O_{\text {aplic }}=P o p \times Q P C_{D Q O}$} & \multirow{3}{*}{ (1) } & DQOaplicada: carga de DQO aplicada (kgDQO aplicada.d $\mathrm{d}^{-1}$ ) \\
\hline & & Pop: População contribuinte (hab.) \\
\hline & & QPC ${ }_{D Q O}$ : Contribuição per capita de DQO $\left(\mathrm{kg} \mathrm{hab}^{-1} \cdot \mathrm{d}^{-1}\right)$ \\
\hline \multirow{2}{*}{$P_{\text {lodo }}=Y \times D Q O_{\text {applicada }}$} & \multirow{2}{*}{$(2)$} & Plodo: Produção total de lodo $\left(\mathrm{kgSST} . \mathrm{d}^{-1}\right)$ \\
\hline & & Y: Produção de lodo $\left(0,10\right.$ a 0,20 kgSST.kgDQO aplicada $\left.^{-1}\right)$ \\
\hline$Q_{\text {lodo }}=\frac{P_{\text {lodo }}}{\left(C_{\text {lodo }} \times \gamma\right)}$ & (3) & $\begin{array}{l}\text { Qlodo: Vazão de lodo }\left(\mathrm{m}^{3} \cdot \mathrm{d}^{-1}\right) \\
\text { Clodo: Teor de sólidos totais }(\% \mathrm{ST}) \\
\text { Y: Massa específica do lodo }\left(\mathrm{kg} \cdot \mathrm{m}^{-3}\right)\end{array}$ \\
\hline
\end{tabular}

Para os cálculos considerou-se a produção média anual e adotou-se o valor de $0,15 \mathrm{kgSST}_{\mathrm{kgDQO}}$ aplicada $^{-1}$ para o coeficiente de produção total de lodo e admitiuse: $5 \%$ de ST (sólidos totais) no lodo na saída do reator anaeróbio, 45\% de ST após o desaguamento e 85\% de ST no lodo seco (combustível) (Rosa et al., 2018; Jordão e Pessôa, 2011). Para o horizonte 2043 utilizou-se dados de população futura atendida conforme plano diretor.

\section{Potencial energético disponível}

A quantidade de energia química obtida com o biogás foi determinada a partir das estimativas do software Probio (versão 1.0) e a energia útil foi calculada pelo método descrito por Bilotta e Ross (2016). O potencial energético do lodo anaeróbio foi determinado a partir da energia química disponível do lodo seco (85\% ST), utilizando-se as equações propostas por Rosa et al. (2018) (equações 4, 5, 6 e 7 Quadro 2).

Quadro 2 - Equações utilizadas para determinar o potencial energético do lodo anaeróbio.

\begin{tabular}{|c|c|c|}
\hline \multirow{3}{*}{\multicolumn{2}{|c|}{$M_{\text {aguaremov }}=Q_{\text {lodo4556 }}-Q_{\text {lod } 08556}$}} & Máguaremov: Massa de água removida (45 para $85 \%$ ST) (kg) \\
\hline & & Qlodo45\%: Vazão do lodo com $45 \%$ ST $\left(\mathrm{m}^{3} \cdot \mathrm{d}^{-1}\right)$ \\
\hline & & Qlodo85\%: Vazão do lodo com $85 \%$ ST $\left(\mathrm{m}^{3} \cdot \mathrm{d}^{-1}\right)$ \\
\hline \multirow{3}{*}{$P_{\text {lodosec }}=\left(\frac{E_{\text {sonlidos }}}{100}\right) \times P_{\text {lodo }}$} & \multirow{3}{*}{$(5)$} & Plodosec: Produção de lodo com 85\% ST (kgSST.d-1 $)$ \\
\hline & & Esólidos: Teor de ST após desidratação (85\% ST) \\
\hline & & Plodo: Produção de lodo $\left(\mathrm{kgSST}^{\left.\mathrm{d} \mathrm{d}^{-3}\right)}\right.$ \\
\hline \multirow{3}{*}{$P E_{\text {lodo }}=P C I_{t} \times P_{\text {tot }}$} & \multirow{3}{*}{ (6) } & PE lodo: Potencial energético do lodo \\
\hline & & PClt: Poder calorífico inferior $\left({\left.\mathrm{MJ} . \mathrm{kg}^{-1}\right)}^{-1}\right.$ \\
\hline & & $P_{\text {tot: }}$ Produção total de lodo $\left(\mathrm{kgST}^{\left.-\mathrm{d}^{-1}\right)}\right.$ \\
\hline \multirow[b]{2}{*}{$P_{E}=Q_{N-R E A L-C H 4} \times P C I_{D} \times E f$} & \multirow[b]{2}{*}{ (7) } & $P_{\mathrm{E}}:$ Potência elétrica disponível $\left(\mathrm{kWh} \cdot \mathrm{d}^{-1}\right)$ \\
\hline & & QN-REAL-CH4: Vazão disponível normalizada $\left(\mathrm{Nm}^{3} \cdot \mathrm{d}^{-1}\right)$ \\
\hline
\end{tabular}




\section{Análise de viabilidade}

$\mathrm{Na}$ avaliação da viabilidade técnica das alternativas de recuperação de energia considerou-se três alternativas distintas: 1) utilização de secador térmico de lodo desaguado com recuperação de biogás e que sejam UGLs ou ETEs que gerenciam o lodo em suas próprias instalações de origem; 2) utilização de secador térmico de lodo desaguado com cogeração (biogás e lodo seco) e que sejam UGLs ou ETEs que gerenciam o lodo em suas próprias instalações de origem; 3) recuperação do biogás em motogerador nas ETEs com população atendida superior a 50 mil habitantes, como recomenda Carvalho (2016), e que transfiram a gestão do lodo para uma UGL.

Realizou-se também consulta a representantes comerciais dos principais fabricantes de secadores térmicos e motogeradores, com o objetivo de obter informações para estimar o consumo de energia dos equipamentos e determinar o investimento necessário. Considerou-se como saída do fluxo de caixa os custos com aquisição do equipamento, gasômetro, tanques de drenagem, dessulfurizador, filtro de carvão ativado e compressor, bem como o custo de instalação, manutenção e depreciação do sistema (Mulinari et al., 2017; Carvalho, 2016), e como entrada do fluxo de caixa pressupôs-se o custo evitado com energia elétrica.

\section{Análise de desempenho das tecnologias}

Após a estimativa dos potenciais energéticos, elaborou-se um índice de avaliação das três alternativas tecnologias de aproveitamento energético para cada ETE da área de estudo, nos cenários de 2017 e 2043. O índice compreendeu: 1) indicador de produtividade (kWh.mês ${ }^{-1}$ útil versus kWh.mês ${ }^{-1}$ produzido), que determina os rendimentos nas conversões (energia química, térmica e elétrica) nas tecnologias analisadas; 2) indicador financeiro (R\$ evitados por kWh.mês-1 versus $\mathrm{R} \$$ investidos por kWh.mês ${ }^{-1}$ ), que relaciona o consumo evitado de energia elétrica e o investimento necessário para implantação da tecnologia. Os cálculos foram realizados utilizando-se as equações 8, 9, 10 (Quadro 3).

Quadro 3 - Equações utilizadas para determinar o potencial energético do lodo anaeróbio.

\begin{tabular}{|c|c|c|}
\hline \multirow{3}{*}{ IP $=\frac{\text { energia útil }}{\text { energia produzida }}$} & \multirow{3}{*}{ (8) } & IP: Indicador de produtividade \\
\hline & & Energia útil: Obtida a partir da tecnologia analisada (kWh.mês ${ }^{-1}$ ) \\
\hline & & $\begin{array}{l}\text { Energia produzida: Obtida a partir da tecnologia analisada } \\
\left(\mathrm{kWh}^{\mathrm{mês}}{ }^{-1}\right)\end{array}$ \\
\hline \multirow{2}{*}{ IF $=\frac{\text { custo evitado }}{\text { custo investido }}$} & \multirow{2}{*}{ (9) } & IF: Indicador financeiro \\
\hline & & Custo evitado: Consumo evitado de energia elétrica \\
\hline
\end{tabular}




\begin{tabular}{|c|c|c|}
\hline & $\left(\mathrm{R} \$ \cdot \mathrm{kWh}^{-1} \cdot \mathrm{mê}^{-1}\right)$ \\
\hline & & $\begin{array}{l}\text { Custo investido: Investimento na tecnologia analisada } \\
\left(\mathrm{R} \$ \cdot \mathrm{kWh}^{-1} \cdot \mathrm{mê}^{-1}\right)\end{array}$ \\
\hline $\mathrm{IFIN}=\frac{\mathrm{IP}+\mathrm{IF}}{2}$ & (10) & IFIN: Índice de avaliação das tecnologias analisadas \\
\hline
\end{tabular}

O índice de avaliação das tecnologias (motogerador ou secador térmico) de recuperação energética do biogás e lodo foi calculado para cada ETE da área de estudo, nos cenários de 2017 e 2043, considerando-se pesos iguais para os indicadores de produtividade e financeiro. Os valores obtidos permitiram comparar as alternativas tecnológicas analisadas e identificar qual o combustível (biogás, lodo seco ou ambos) mais adequado para cada ETE.

\section{Resultados e discussão}

\section{Potencial energético: cenário 2017 e 2043}

A análise das informações fornecidas pela companhia de saneamento mostrou que algumas ETEs de pequeno porte (população inferior a $40 \mathrm{mil}$ habitantes) transferem o lodo desaguado (com 40 a 50\% ST) para ETEs maiores, denominadas Unidades de Gerenciamento de Lodo (UGLs). No cenário de 2017, observou-se que 18 das 24 ETEs integravam UGLs, enquanto 6 ETEs gerenciavam seu próprio lodo. Conforme o plano diretor da companhia de saneamento, 23 ETEs estarão integradas ao sistema de UGLs no cenário de 2043 e outras 4 ETEs farão a gestão do lodo em suas instalações, totalizando 29 plantas com reator UASB.

Verificou-se que as 5 maiores ETEs (1.359.575 habitantes atendidos) representavam, em 2017, 85\% do potencial energético total (produção de lodo seco: $290 \mathrm{~m}^{3} . \mathrm{d}^{-1}$; produção de biogás: 10.658,0 Nm $\mathrm{Nm}^{3} \cdot \mathrm{d}^{-1}$; energia disponível: 223,0 MWh.d1). No cenário de 2043, os cálculos apontaram que 8 ETEs devem responder por $87 \%$ do potencial energético total da RMC (produção de lodo seco: $594,4 \mathrm{~m}^{3} \cdot \mathrm{d}^{-1}$; produção de biogás: $27.823,0 \mathrm{Nm}^{3} \cdot \mathrm{d}^{-1}$; energia disponível: 462,0 MWh.d $\mathrm{d}^{-1}$ ), isto é, um incremento de $107 \%$ em 25 anos. O aumento no número de ETEs de grande porte, em 2043, se deve à previsão de desativação de 4 unidades e o bombeamento do esgoto dessas ETEs para outras cuja capacidade será ampliada para atender a nova demanda. A Figura 2 mostra a distribuição espacial dos resultados. 
Figura 02 - Potencial energético disponível nas ETEs da área de estudo.

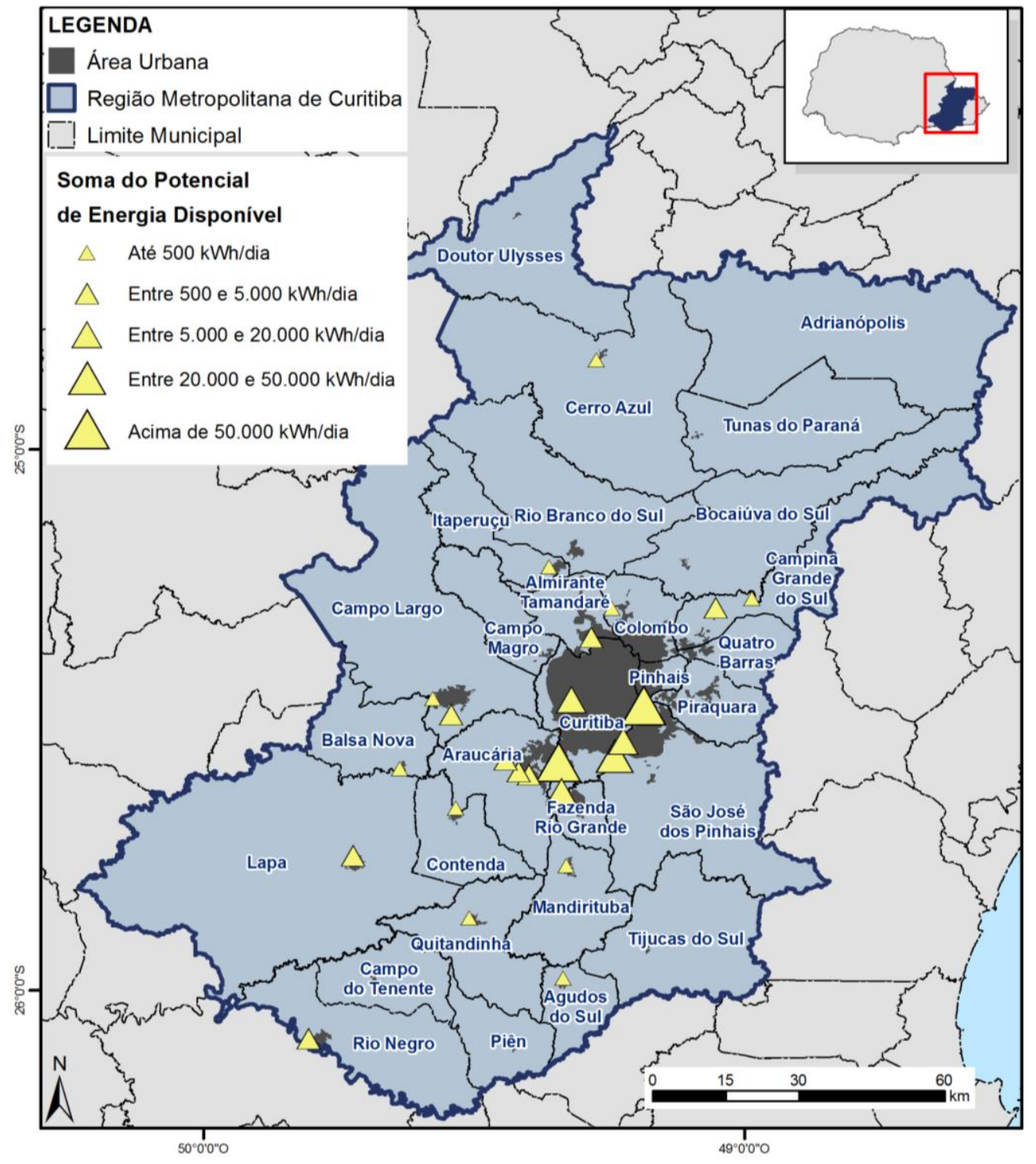

a) Cenário 2017. 


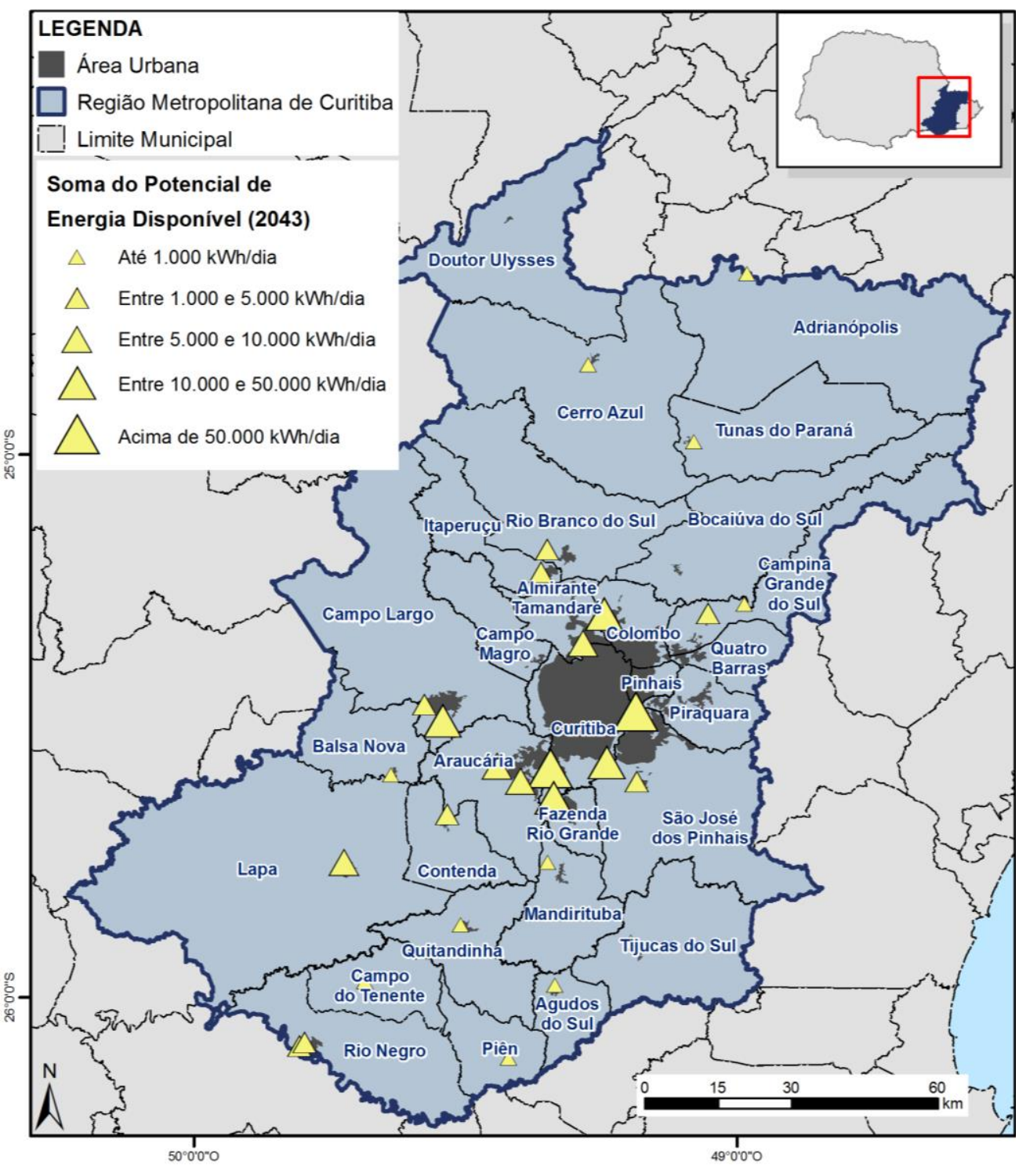

b) Cenário 2043.

\section{Análise das alternativas}

As alternativas consideradas na análise foram: a) motogerador para população atendida superior a 50 mil habitantes, como recomenda Carvalho (2016); b) secador térmico de lodo alimentado exclusivamente com biogás (modelo básico, fabricante Pieralisi, evapora $1.000 \mathrm{~kg} \cdot \mathrm{h}^{-1}$ de água, capacidade $2.650 \mathrm{~m}^{3} \cdot \mathrm{h}^{-1}$, consumo 70 kWh); b) cogeração com biogás e lodo seco ( $85 \%$ ST) em secador térmico (fabricante Albrecht, modelo DRAKO, evapora $520 \mathrm{~kg} \cdot \mathrm{h}^{-1}$ de água, capacidade 700 $\mathrm{m}^{3} \cdot \mathrm{h}^{-1}$, consumo $\left.25 \mathrm{kWh}\right)$. O Quadro 4 resume os resultados. 
Quadro 4 - Resultado da análise de alternativas.

\begin{tabular}{|l|c|l|}
\hline CENÁRIO & CLASSE & PROPOSTA \\
\hline \multirow{2}{*}{2017} & 6 UGLs & Implantar secador térmico com recuperação de biogás ou cogeração \\
\cline { 2 - 3 } & 18 ETEs & Destinar o lodo para UGLs (não há viabilidade técnica) \\
\hline \multirow{3}{*}{2043} & 6 UGLs & Implantar secador térmico com recuperação de biogás ou cogeração \\
\cline { 2 - 3 } & 5 ETEs & Implantar motogerador \\
\cline { 2 - 3 } & 18 ETEs & Destinar o lodo para UGLs (não há viabilidade técnica) \\
\hline
\end{tabular}

UGL: Unidade de gestão de lodo

As 6 ETEs que integravam o sistema UGL no cenário 2017 apresentaram produção de biogás $\left(10.719,0 \mathrm{Nm}^{3} . \mathrm{d}^{-1}\right)$ e lodo $\left(24.610,4 \mathrm{kgSST}^{-1} \mathrm{~d}^{-1}\right)$ suficiente para viabilizar a implantação da tecnologia de secagem térmica do lodo desaguado ou para cogeração (obtenção de energia a partir da combustão do biogás e lodo seco). Das 18 ETEs retantes, 5 serão desativadas e as outras 13 não resultaram em viabilidade técnica para o motogerador (produção de $\mathrm{CH}_{4}: 1$ a $253 \mathrm{Nm}^{3} . \mathrm{d}^{-1}$ ) ou para o secador térmico (o lodo produzido nessas plantas é destinado para UGLs).

Portanto, sugere-se a manutenção da configuração atual (destinação do lodo para UGLs e eventual queima do biogás). Para o cenário de 2043, as 6 UGLs mantêm a viabilidade técnica e 5 ETEs passam a apresentar potencial para implantação de motogerador (produção de $\mathrm{CH}_{4}: 545$ a $1.972 \mathrm{Nm}^{3} . \mathrm{d}^{-1}$ ). As outras 18 ETEs permanecem inviáveis, semelhante ao cenário 2017, sendo recomendada a destinação do lodo para a UGL mais próxima. A Figura 3 mostra a distribuição espacial das alternativas para as 29 ETEs no horizonte de 2043. O Quadro 5 compara os investimentos (depreciação de 20 anos) e o consumo de energia elétrica evitado com a implantação das tecnologias propostas nos dois cenários. 
Figura 03 - Proposta de gestão do biogás e lodo das ETEs da área de estudo (ano 2043).

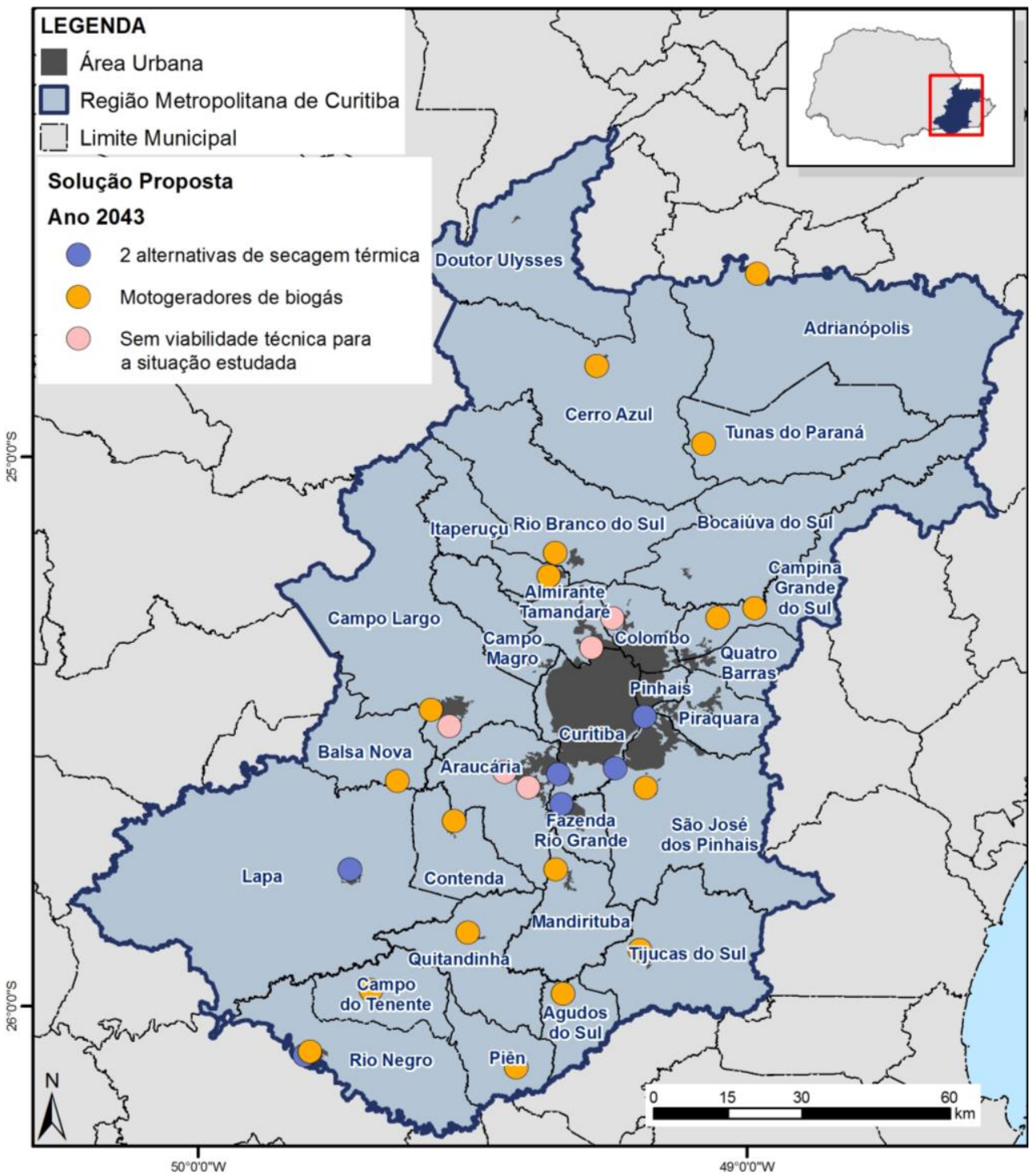

Quadro 5 - Resultado da análise de viabilidade financeira das alternativas.

\begin{tabular}{|c|c|c|c|c|}
\hline CENÁRIO & CLASSE & $\begin{array}{l}\text { INVESTIMENTO } \\
(\mathrm{R} \$)\end{array}$ & $\begin{array}{l}\text { CONSUMO EVITADO } \\
\left(\text { MWh.mês }^{-1}\right)\end{array}$ & $\begin{array}{c}\text { RELAÇÃO } \\
\mathrm{R} \$ \text { / MWh.mês }{ }^{-1}\end{array}$ \\
\hline \multirow{2}{*}{2017} & \multirow{2}{*}{6 UGLs } & $17.756 .886,43^{(1)}$ & $848.515,0^{(1)}$ & 20,90 \\
\hline & & $23.981 .236,36^{(2)}$ & $1.426 .505,0^{(2)}$ & 16,80 \\
\hline \multirow{3}{*}{2043} & \multirow{2}{*}{6 UGLs } & $33.112 .264,98^{(1)}$ & $1.706 .642,0^{(1)}$ & 19,40 \\
\hline & & $49.276 .598,06^{(2)}$ & $2.895 .829,0^{(2)}$ & 17,00 \\
\hline & 5 ETEs & $15.181 .694,67^{(3)}$ & $654.196,0^{(3)}$ & 23,20 \\
\hline
\end{tabular}

1) Secagem térmica do lodo com biogás. 2) Secagem térmica do lodo com biogás e combustão do lodo seco. 3) Motogerador. 
As estimativas realizadas para as alternativas 1, 2 e 3 (Quadro 5) mostraram o potencial de redução significativa da demanda externa de energia elétrica das ETEs analisadas, tanto no cenário de 2017 quanto 2043 (consumo máximo evitado: 3.550,0 GWh.mês ${ }^{-1}$ ). A implantação de motogeradores nas ETEs que ainda serão construídas apresentou a melhor relação custo/benefício ( $\mathrm{R} \$ 23,20$ / MWh.mês $\left.{ }^{-1}\right)$, assim como a secagem térmica do lodo com biogás gerado nas UGLs ( $R \$ 20,90$ e R\$19,40 / MWh.mês ${ }^{-1}$ ). Destaca-se, porém, que essas duas alternativas podem ser inseridas concomitantemente, pois utilizam biogás de fontes distintas. Os resultados obtidos neste trabalho, em termos de quantidade de energia útil disponível em nas plantas de tratamento, são semelhantes a outros trabalhos que utilizaram biogás e lodo seco como fontes para obtenção de energia renovável (Rosa et al., 2018; Mulinari et al., 2017; Carvalho, 2016; Bilotta e Ross, 2016).

Embora o lodo com $90 \%$ de ST tenha alto poder calorífico $\left(2,5 \mathrm{kWh}^{\mathrm{kg}}{ }^{-1}\right)$ (Rosa et al., 2019), o rendimento na conversão de energia química em energia elétrica é baixo (17\% segundo o fabricante do secador térmico rotativo), e isso reduz a relação custo/benefício. O investimento estimado para as alternativas 1 e 2 (Quadro 5), nas 6 UGLs, considerou custos proporcionais ao volume de lodo produzido por hora e um adicional de $20 \%$ quando o dimensionamento do secador térmico fosse menor que o valor consultado, conforme recomendação do fabricante. Além disso, admitiu-se o funcionamento do equipamento em $70 \%$ do tempo, para se determinar o consumo mensal de energia (Rosa et al., 2018).

A análise das alternativas para o cenário de 2043 pode auxiliar a companhia de saneamento no planejamento da recuperação energética dos subprodutos do tratamento de esgoto na área de estudo, de modo a viabilizar a implantação das estratégias avaliadas neste trabalho. Além disso, em um horizonte de 25 anos podem surgir tecnologias mais eficientes na conversão energética, ou ainda a comercialização no Brasil de tecnologias já existentes em países mais desenvolvidos no assunto, como é o caso da pirólise (Karaca et al., 2018), bem como a redução do valor investido para a aquisição de equipamentos, viabilizando, assim, a expansão dessa prática em ETEs brasileiras.

Apesar deste estudo tratar de ETEs anaeróbias, a digestão de lodo aeróbio em condições anaeróbias também pode ser uma fonte de geração de biogás. Além disso, a energia térmica proveniente do biogás e do lodo pode ser aproveitada em outras alternativas tecnológicas, como no aquecimento do efluente para otimizar o 
desempenho do reator biológico ou mesmo na secagem de lodo (Possetti et al., 2012; Borges et al., 2009). Nesse sentido, ETEs que não apresentam viabilidade para geração de energia elétrica podem ser favoráveis para obtenção de energia térmica.

\section{Análise de desempenho das tecnologias}

Para cada uma das ETEs com viabilidade técnica (Quadro 4) gerou-se um índice de avaliação de desempenho em relação às tecnologias propostas. Os índices foram calculados a partir do indicador de produtividade (kWh.mês ${ }^{-1}$ útil versus kWh.mês ${ }^{-1}$ produzido) e do indicador financeiro ( $\mathrm{R} \$$ evitados por kWh.mês ${ }^{-1}$ versus $R$ \$ investidos por kWh.mês ${ }^{-1}$ ) e analisados conforme a seguinte classificação:

- <0,15: Baixo (não resulta em viabilidade).

- $\quad \geq 0,15$ e < 0,30: Médio (não resulta em viabilidade, porém sugere-se estudos com outras alternativas que possam ser mais vantajosas).

- $\quad \geq 0,30$ e < 0,40: Alto (pode resultar em viabilidade aceitável, porém sugere-se uma análise detalhada das tecnologias para verificar as particularidades de cada planta).

- $\geq 0,40$ : Muito alto (representa efetiva viabilidade, compatível com o rendimento de conversão de energia química em energia elétrica).

A classificação proposta se baseia no rendimento da conversão de energia química em energia térmica e elétrica (Rosa et al., 2018; Rosa et al., 2016; Seiple et al., 2017), considerando-se as tecnologias disponíveis no país. Nesse sentido, sugere-se um estudo mais aprofundado que permita identificar outros indicadores de desempenho, bem como aperfeiçoar a classificação apresentada neste trabalho. 
A distribuição espacial dos resultados do índice de análise de desempenho para ambos os cenários (2017 e 2043) pode ser visualizada na Figura 4.

Figura 04 - Índice de avaliação de desempenho das ETEs na área de estudo.

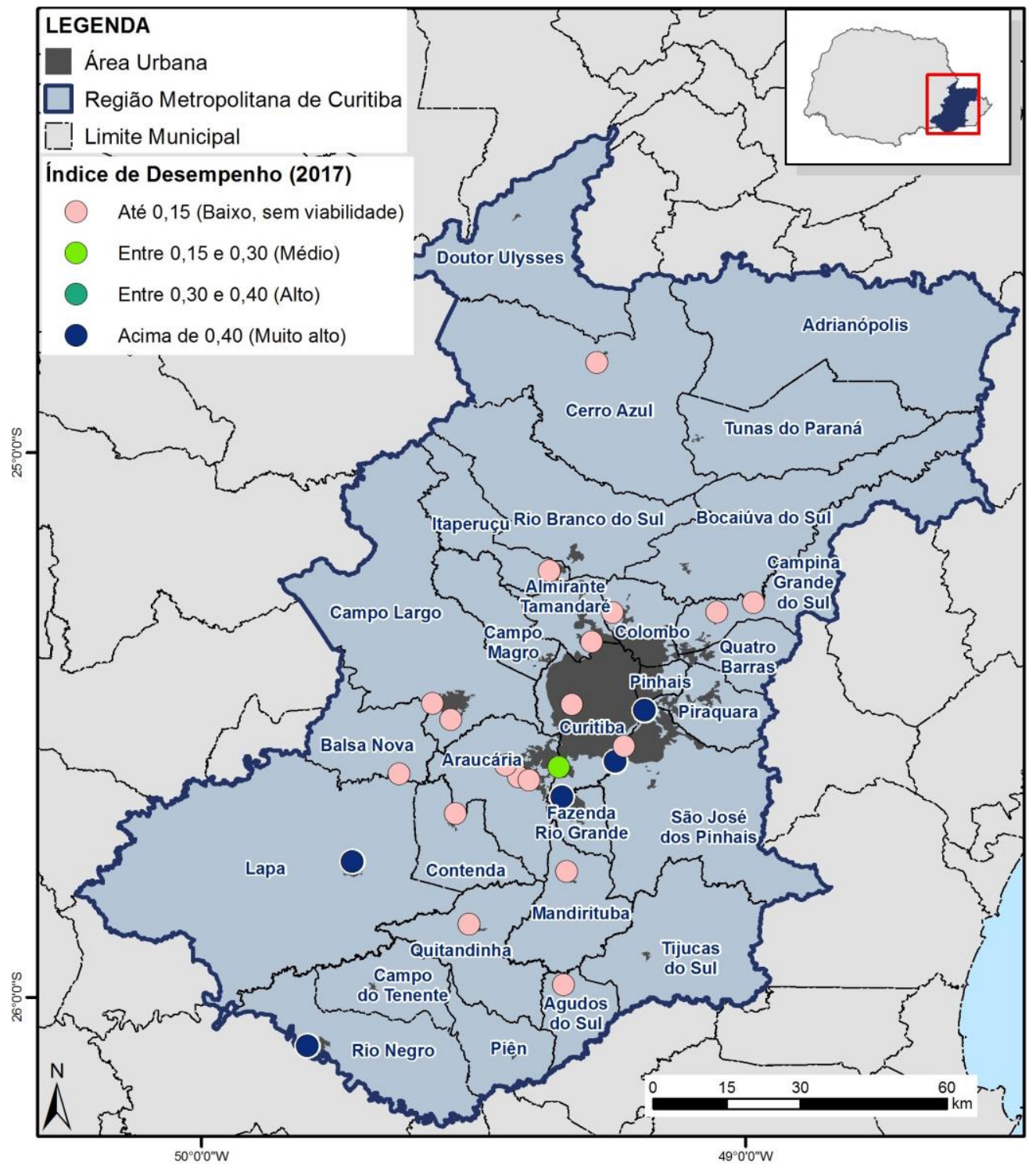

a) Cenário 2017. 


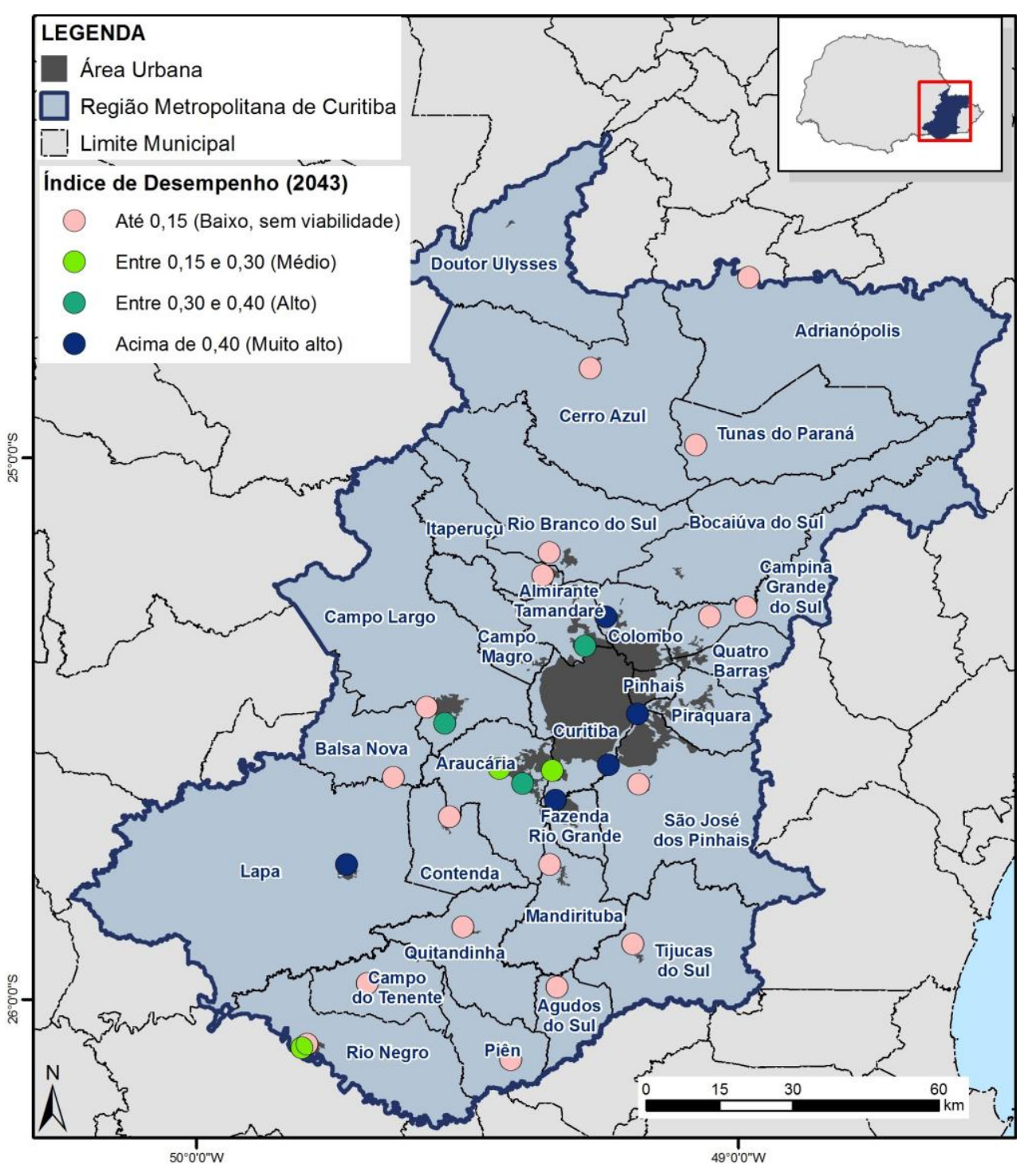

b) Cenário 2043.

No ano 2017, 5 ETEs foram classificadas com índice "muito alto" de desempenho para recuperação energética e apenas 1 ETE obteve índice "médio", dentre as 6 ETEs com viabilidade técnica. No cenário projetado para 2043, 5 ETEs alcançaram índice de desempenho "muito alto", 3 ETEs obtiveram índice "alto" e 3 ETEs com índice "médio", dentre as 11 ETEs identificadas como tecnicamente viáveis (Quadro 4). Os índices "muito alto" e "alto" indicam condições favoráveis para implantação de secagem térmica com recuperação de biogás, ou ainda cogeração com lodo seco, e emprego de motogerador para geração de energia elétrica a partir da combustão do biogás. Para as ETEs enquadradas com índice "médio" recomenda-se uma análise mais aprofundada caso a caso, considerando-se, 
inclusive, a avaliação de outras alternativas tecnológicas, como o aproveitamento da energia térmica na combustão do biogás para secagem de lodo.

Os resultados apresentados na Figura 4 mostram os índices de desempenho das ETEs estimados a partir da simulação da produção de biogás na condição conservadora (software Probio), isto é, baixo rendimento na formação de metano. No entanto, a produtividade pode ser incrementada por meio de investimento em infraestrutura e de melhoria contínua na operação das ETEs, sobretudo nos reatores biológicos, bem como no controle e redução de perdas de biogás no sistema. Além disso, a utilização de medidores de produção de metano permite precisar a real disponibilidade de bioenergia nas plantas de tratamento de esgoto.

A recuperação de energia em ETEs é uma prática que demanda elevado investimento (Carvalho, 2016), todavia, os projetos de bioenergia podem ser viabilizados por meio de mecanismos de incentivo financeiro (por exemplo, mercado de créditos de carbono) e regulação de emissões (por exemplo, tarifação de carbono), além de consórcios entre municipais fronteiriços, dentre outras ações (Santos et al., 2016).

\section{Considerações Finais}

Este trabalho propõe estratégias para o aproveitamento energético do biogás e lodo de estações de tratamento anaeróbio de esgoto (ETEs) da Região Metropolitana de Curitiba. As alternativas tecnologias avaliadas foram: 1) secagem térmica de lodo com biogás; 2$)$ secagem térmica de lodo com biogás e combustão do lodo seco ( $85 \%$ sólidos totais); 3) motogerador movido a biogás.

Verificou-se que pelo menos $26 \%$ das ETEs da RMC apresentam viabilidade para recuperação energética do biogás e lodo seco no cenário atual e esse percentual passa para 38\% no horizonte de 2043. Em 2017, 6 ETEs integrantes do sistema centralizado de gestão do lodo, denominado unidade de gerenciamento (UGL), apresentaram viabilidade para implantação das alternativas 1 e 2 (consumo médio evitado de $840 \mathrm{MWh} \cdot \mathrm{d}^{-1}$ ). As outras $18 \mathrm{ETEs}$ não apresentaram viabilidade técnica para utilização de nenhuma das três alternativas avaliadas, pois 5 delas serão desativadas e nas demais ETEs a produção de biogás é insuficiente (1 a 253 $\left.\mathrm{Nm}^{3} \mathrm{CH}_{4} . \mathrm{d}^{-1}\right)$ e o lodo é destinado para UGLs. Nesses casos sugere-se a manutenção da configuração atual (destinação do lodo para UGLs) e eventual queima do biogás nas ETEs que não apresentaram viabilidade técnica. Para o 
cenário de 2043, as 6 UGLs mantêm a viabilidade técnica para as alternativas 1 e 2 (consumo médio evitado de $1.680 \mathrm{MWh}$.mês $^{-1}$ ) e 5 ETEs se tornam viáveis apenas para implantação de motogerador movido a biogás (545 a $1.972 \mathrm{Nm}^{3} \mathrm{CH}_{4} . \mathrm{d}^{-1}$; consumo médio evitado de 655 MWh.mês ${ }^{-1}$ ), pois o lodo produzido nessas unidades será transferido para UGLs (portanto, não há viabilidade para as alternativas 1 e 2). As outras 18 ETEs permanecem inviáveis, como no ano 2017, sendo recomendada a destinação do lodo para a UGL mais próxima e a queima do biogás.

A utilização de um índice de desempenho construído a partir de indicadores de produtividade e financeiro mostrou-se uma estratégia promissora na gestão de alternativas de recuperação energética do biogás e lodo seco. Outros indicadores podem ser incorporados para aperfeiçoar a capacidade de resposta do índice, bem como a classificação proposta pode ser revista, considerando-se outras tecnológicas e novos critérios de avaliação de risco e oportunidade para a companhia.

\section{REFERÊNCIAS}

AMBIENT. Biogás de ETE para geração de energia elétrica: ETE - Ribeirão Preto. Ribeirão Preto, 2014. Disponível em: www.abconsindcon.com.br/ena/edicaoena?id=6\&dia=1\&sala=3\&show=listar Acesso em: 30/07/2019.

ANDREOLI, C. V.; VON SPERLING, M.; Fernandes F. Lodo de esgotos: tratamento e disposição final. $1^{a}$ ed. Belo Horizonte: DESA/UFMG, 2001. 484 p.

BATISTELLA, L. Avaliação das emissões gasosas geradas na combustão de lodo de esgoto sanitário em combustor de leito móvel. 2015. Tese (Doutorado em Engenharia Química) - Universidade Federal de Santa Catarina, Florianópolis, 168 p.

Bilotta, P.; Ross, B. Z. L. Estimativa de geração de energia e emissão evitada de gás de efeito estufa na recuperação de biogás produzido em estação de tratamento de esgotos.

Revista Engenharia Sanitária e Ambiental, v. 21, p. 275-282, 2016.

BORGES, E. S. M.; GODINHo, V. M.; BEJAR, D. O.; CHERNICHARO, C. A. L. Tratamento térmico de lodo anaeróbio com utilização de biogás gerado em reatores UASB: avaliação da auto-sustentabilidade do sistema e do efeito sobre a higienização e a desidratação do lodo.

Revista Engenharia Sanitária e Ambiental, v. 14, n. 3, p. 337-346, 2009.

BRASIL. MINISTÉRIO DAS CIDADES. Tecnologias de digestão anaeróbia com relevância para o Brasil: substratos, digestores e uso de biogás - PROBIOGÁs.

Brasília: Secretaria Nacional de Saneamento Ambiental, Ministério das Cidades, Deutsche Gesellschaft Für Internationale Zusammenarbeit, 2015, 83 p.

CARNEIRO, M., BILOTTA, P. Malucelli, L. C., OCH, S. H., Carvalho Filho, M. A. S. Sludge and scum blends from water and wastewater plants for energy recovering toward a circular economy perspective. International Journal of Environmental Science and Technology, 2020. https://doi.org/10.1007/s13762-020-02727-8 
CARVALHO, M. E. Diretrizes para promoção de uma economia de baixo carbono no setor de esgotamento sanitário paranaense a partir da recuperação do biogás gerado em reatores anaeróbios. 2016. Dissertação (Mestrado em Governança e Sustentabilidade) - Instituto Superior de Administração e Economia (ISAE/FGV), Curitiba, 118 p.

CHERNICHARO, C. A. L.; VAN LIER, J. B.; NOYOLA, A.; RIBEIRO, T. B. Anaerobic sewage treatment: state of art, constrains and challenges. Reviews in Environmental Science and Bio/Technology, v. 14, n. 4, p. 649-679, 2015.

COPASA. COMPANHIA DE SANEAMENTO DE MINAS GERAIS. A Experiência da COPASA MG no aproveitamento energético do biogás na ETE Arrudas. Belo Horizonte, COPASA, 2013. Disponível em: www.funasa.gov.br/site/wpcontent/uploads/2013/05/Marcelo Monachesi.pdf Acesso em: 30/07/2019.

COPASA. COMPANHIA DE SANEAMENTO DE MINAS GERAIS. ETE Sustentável: Aproveitamento do Biogás. Belo Horizonte, COPASA, 2016. Disponível em: www.copasa.com.br/wps/portal/internet/esgotamento-sanitario/valorizacao-doesgoto/conteudos/ete-sustentavel Acessado em: 30/07/2018.

FRAIA, S. DI; MASSAROTTI, N.; VANOLI, L. A novel energy assessment of urban wastewater treatment plants. Energy Conservation and Management, v. 163, p. 304-313, 2018.

IPCC. INTERGOVERNMENTAL PANEL ON CLIMATE CHANGE. Climate Change 2014: Synthesis Report. Genebra/Suíça: IPCC/WMO, 2015. 169 p.

IPARDES. INSTITUTO PARANAENSE DE DESENVOLVIMENTO ECONÔMICO E SOCIAL. Projeção da população dos municípios do Paraná, por sexo e grupos de idade, para o período 2017-2040. Curitiba/PR: SEPL, 2017. Disponível em: www.ipardes.gov.br Acesso: 16/07/2019.

JORDÃO, E. P.; PESSÔA, C. A. Tratamento de Esgotos Domésticos. 6ª ed. Rio de Janeiro: ABES, 2011, $1050 \mathrm{p}$.

KARACA, C.; SÖZEN, S.; ORHON, D.; Okutan, H. High temperature pyrolysis of sewage sludge as a sustainable process for energy recovery. Waste Management, v. 78, p. 217226, 2018.

KOGA, P. Geração de energia renovável a partir dos subprodutos de uma estação de tratamento anaeróbia de esgotos. 2016. Dissertação (Mestrado em Meio Ambiente Urbano e Industrial) - Universidade Federal do Paraná, Curitiba, 2016. 140 p.

METCALF, L.; EDDY, H. P. Tratamento de Efluentes e Recuperação de Recursos. 6르 ed. Tradução: Ivanildo Hespanhol, José Carlos Mierzwa. Porto Alegre: AMGH, 2016. 1980 p.

MULINARI, R.; BILOTTA, P.; POSSETTI, G. R. C. Análise da sustentabilidade energética da implantação de um secador térmico de lodo usando biogás e lodo seco como combustível em uma planta de tratamento anaeróbio de esgoto sanitário. In: Anais do 29 Congresso Brasileiro de Engenharia Sanitária e Ambiental, São Paulo: ABES, 2017.

NOYOLA, A.; MORGAN-SAGASTUME, J. M.; LÓPEZ-HERNÁNDEZ, J. E. Treatment of biogas produced in anaerobic reactors for domestic wastewater: odor control and energy/resource recovery. Reviews in Environmental Science and Biotechnology, v. 5, p. 93-114, 2006. 
POSSETTI, G. R. C.; JASINSKI, V. P.; ANDREOLI, C. V.; BITTENCOURT, S.; CARNEIRO, C. Sistema térmico de higienização de lodo de esgoto movido a biogás para ETEs de médio e pequeno porte. In: Anais do 15 Simpósio Luso Brasileiro de Engenharia Sanitária e Ambiental, Belo Horizonte: ABES, 2012.

ROSA, L. G.; CANOVA, A. D.; SOUZA, G. C. B.; BILOTTA, P.; CARNEIRO, M.; POSSETTI, G. R. C.; CARVALHO FILHO, M. A. S. Energia liberada na combustão de lodo anaeróbio, aeróbio e mistura provenientes de estação de tratamento de esgoto. In: Org. Feilstrecker, M.; Kolicheski, M.B. Meio Ambiente Urbano e Industrial: tecnologias ambientais. Curitiba: Ed. UFPR/MAUI, 2019, p. 119-128.

ROSA, A. P.; Nevez, R. C.; CHERNICHARO, C. A. L. Aproveitamento energético dos subprodutos, lodo e biogás, a partir do tratamento anaeróbio de efluentes pelo uso de processos termoquímicos. Revista Engenharia na Agricultura, v. 26, p. 26-34, 2018.

ROSA, A. P.; LOBATO, L. C. S.; BORGES, J. M. Melo, G. C. B.; Chernicharo, C. A. L. Potencial energético e alternativas para o aproveitamento do biogás e lodo de reatores UASB: estudo de caso Estação de tratamento de efluentes Laboreaux (Itabira). Revista Engenharia Sanitária e Ambiental, v. 21, n. 2, p. 315-328, 2016.

SANEPAR. COMPANHIA DE SANEAMENTO DO PARANÁ. Plano Diretor do Sistema de Esgotamento Sanitário Integrado de Curitiba e Região Metropolitana (SEIC). Curitiba, SANEPAR, 2015. 225p.

SANEPAR. COMPANHIA DE SANEAMENTO DO PARANÁ. Experiências da SANEPAR em bioenergia e eficiência energética. IV Seminário Internacional de Engenharia de Saúde Pública. Curitiba, 2013. Disponível em: <www.funasa.gov.br/site/wpcontent/uploads/2013/05/Gustavo 02.pdf> Acesso: 30/08/2019.

SANTOS, I. F. S.; BARROS, R. M.; FILHO, G. L. T. Electricity generation from biogas of anaerobic wastewater treatment plants in Brazil: an assessment of feasibility and potential. Journal of Cleaner Production, v. 126, p. 504-514, 2016.

SEIPLE, T. E.; COLEMAN, A. M.; SKAGGS, R. L. Municipal wastewater sludge as a sustainable bioresource in the United States. Journal of Environmental Management, $v$. 197, p. 673-680, 2017.

TYAGI, V. K.; LO, S. Sludge: A waste or renewable source for energy and resources recovery? Renewable and Sustainable Energy Reviews, v. 25, p. 708-728, 2013. Von Sperling, M. Urban wastewater treatment in Brazil. Technical Note IDB-TN-970, InterAmerican Development Bank, 2016, p. 102.

\section{NOTAS DE AUTOR}

\section{CONTRIBUIÇÃO DE AUTORIA}

Christian Taschelmayer: Análise de dados, elaboração do manuscrito, participação ativa da discussão dos resultados.

Patricia Bilotta: Concepção, coleta de dados, revisão e aprovação da versão final do trabalho.

FINANCIAMENTO

Não se aplica.

CONSENTIMENTO DE USO DE IMAGEM

Não se aplica. 
APROVAÇÃO DE COMITÊ DE ÉTICA EM PESQUISA

Não se aplica.

\section{CONFLITO DE INTERESSES}

Não se aplica.

\section{LICENÇA DE USO}

Este artigo está licenciado sob a Licença Creative Commons CC-BY. Com essa licença você pode compartilhar, adaptar, criar para qualquer fim, desde que atribua a autoria da obra.

\section{HISTÓRICO}

Recebido em: 24-09-2019

Aprovado em: 15-04-2021 